\title{
REVERSIBLE EFFECTS OF MONOTHIOL (D-PENICILLAMINE) AND DITHIOL (DIMERCAPTOSUCCINIC ACID) CHELATING COMPOUNDS ON METHYLMERCURY-INHIBITED CHOLINE ACETYLTRANSFERASE ACTIVITY AND HIGH AFFINITY CHOLINE UPTAKE
}

\author{
Haruo KOBAYASHI, Akira YUYAMA, Yoshiaki TOKONABE* \\ and Naonori MATSUSAKA** \\ Department of Veteririary Pharmacology and * Veterinary Public Health, \\ Faculty of Agriculture. Iwate University. Morioka 020. Japan
}

Accepted March 29, 1982

\begin{abstract}
The effects of thiol compounds on methylmercury chloride (MMC)-inhibited choline acetyltransferase (ChAT) activity and MMCinhibited high affinity choline uptake of rat brain tissue were studied in vitro. D-penicillamine (D-PC) and dimercaptosuccinic acid (DMS) reversed the MMC-inhibited ChAT activity dose-dependently. Equilibrium dialysis of MMC-inhibited ChAT against the buffer containing $10^{-3} \mathrm{M} \mathrm{D-PC} \mathrm{reversed}$ the ChAT activity almost completely. The reversal effect of D-PC (monothiol compound) on MMC-inhibited ChAT was significantly more potent than that of DMS (dithiol compound). D-PC and DMS almost equally reversed the MMC-inhibited high affinity choline uptake by synaptosomes in a dose dependent fashion. Washing with a solution containing D-PC or DMS equally reversed the MMC-inhibited high affinity choline uptake in a dosedependent fashion. Neither D-PC nor DMS could reverse the hemicholinium -3-inhibited high affinity choline uptake.
\end{abstract}

It is well known that methylmercury accumulation in nervous tissue causes various neurological disturbances (1-3), although the mechanism by which this substance produces neurotoxicity is not fully known. From the present series of studies (4-6), however, it was postulated that one of the possible mechanisms underlying methylmercury neurotoxicity might be related to cholinergic dysfunction. It is known that methylmercury chloride (MMC) inhibits choline acetyltransferase (ChAT) activity and the high affinity uptake of choline into the brain

* Present address: Fukuno Health Center, Fukunocho, Toyama 935-15. Japan synaptosomes in vitro $(4,7)$. Since mercury binds potently to the sulfhydryl groups, it is anticipated that these inhibitory actions of MMC may be mediated by binding to the thiol groups that participate in the catalytic reaction of ChAT and in a mechanism of high affinity choline uptake. ChAT is known to be an SH-enzyme (8). Although the mechanism of the high affinity choline uptake is fully unknown, since mercury can form coordination bonds with membrane functional groups such as sulfhydryl, hydroxyl, carbonyl. phosphate, and amino (9) groups, it may thereby affect choline uptake.

Sulfhydryl chelating agents such as cysteine, dimercaptopropanol (BAL) and 
penicillamine $(P C)$ are used for the clinical treatment of mercury poisoning. Since BAL, a potent dithiol chelating agent, has a high toxicity by itself and is water-insoluble, the modification of BAL led to the synthesis of water-soluble derivatives such as 2. 3 dimercaptosuccinic acid (DMS) and 2, 3dimercaptopropanol sulfonate which have been reported to be less toxic than the parent compound (10-16). These watersoluble dithiols are generally accepted to be more potent than monothiols in removing mercury accumulated in tissues.

On the other hand, it was, however. reported that D-PC, a monothiol, was mare effective than BAL in reducing the mercury content of the brain and in preventing neurotoxicity in rats exposed to methylmercury (16). Since methylmercury has a hydrophobic property and can interact with protein moieties other than the thiol groups $(17,18)$, the reversible effectiveness of thiol compounds cannot simply be attributed to the number of thiol groups in the molecule.

It was reported that thiol chelating agents. such cysteine, could partly restore ChAT activity and high affinity choline uptake which were previously inhibited by mercury compounds in vitro $(8,19)$.

This study was carried out to determine whether the inhibitory effects of MMC on ChAT activity and high affinity choline uptake were related to the thiol groups and to clarify how they could be reversed by monothiol and dithiol chelating compounds. The thiol compounds used in this study were D-PC and DMS.

\section{MATERIALS AND METHODS}

Experiments on choline acetyltransferase: Male Wistar rats weighing 120-150 g were used. ChAT was prepared from the freezedried powder of rat brains by the method of Ebashi (20). The enzyme activity was determined radiochemically by a slight modifi- cation of the method of Shrier and Shuster (21) at $38^{\circ} \mathrm{C}$ for $20 \mathrm{~min}$ with $500 \mu \mathrm{M}$ choline chloride (100-500 $\mu \mathrm{M}$ choline was used in kinetic analysis) and $50 \mu \mathrm{M}$ acetyl-CoA as substrates. The material used was $\left[1-{ }^{4} \mathrm{C}\right]$ acetyl coenzyme A $(55.4 \mathrm{mCi} / \mathrm{mmole})$ purchased from the Radiochemical Centre. Amersham. It was diluted to $50 \mu \mathrm{M}$ in each assay mixture with nonradioactive acetylCOA, which had been synthesized from COA (Kohijin Co., Ltd.. Tokyo) by the method of Shrier and Shuster (21).

The ability of chelating agents to reverse the inhibited ChAT activity was determined by first incubating the ChAT preparation with an appropriate concentration of $M M C$ at $0^{\circ} \mathrm{C}$ for $5 \mathrm{~min}$, then adding the chelating agent, and incubating in a medium containing 500 $/ \mathrm{M}$ choline (final concentration) at $38^{\circ} \mathrm{C}$ for an additional 20 min.

Dialysis of MMC-inhibited choline acetyltransferase against phosphate buffer containing thiol-chelating compound: The ChAT preparation $(0.5 \mathrm{ml})$ was preincubated with an equal volume of $4 \times 10^{-4} \mathrm{MMMC}$ at $0^{\circ} \mathrm{C}$ for 10 min and dialyzed in a cellulose tubing bag (size 8/32) against 1 l of $0.01 \mathrm{M}$ sodium phosphate buffer ( $\mathrm{pH} \mathrm{6.3)} \mathrm{in} \mathrm{the} \mathrm{absence}$ (control) or presence of a $1 \mathrm{mM}$ thiolchelating compound (D-PC or DMS) at $0^{\circ} \mathrm{C}$ for 1 to $6 \mathrm{hr}$. At 1, 3, and 6 hr of dialysis, the ChAT activity of the solution in the bag was determined and expressed as a percent of that of the undialyzed intact ChAT preparation.

Experiments on high affinity choline uptake: The rat forebrain was used to prepare a crude synaptosomal preparation by the method of Gray and Whittaker (22). It was homogenized in 10 volumes of $0.32 \mathrm{M}$ ice-cold sucrose solution and centrifuged at $1.000 \mathrm{~g}$ for $10 \mathrm{~min}$ at $0^{\circ} \mathrm{C}$. The pellet was discarded, and the supernatant centrifuged at $10,000 \mathrm{~g}$ for $20 \mathrm{~min}$ at $0^{\circ} \mathrm{C}$. The resulting crude synaptosomal pellet was resuspended in 20 volumes of $0.32 \mathrm{M}$ sucrose. The high affinity choline 
uptake was determined with 0.3 to $5.0 \mathrm{kM}$ choline chloride containing $0.5 \mu \mathrm{Ci}$ of [methyl- ${ }^{14} \mathrm{C}$ ] choline (New England Nuclear Co., Boston) by the modification of the method of Murrin et al. (23) as previously described (4) in which $0.5 \mathrm{mM}$ neostigmine was used as a cholinesterase inhibitor.

The crude synaptosomal preparation was preincubated with $\mathrm{MMC}\left(\mathrm{O}\right.$ to $\left.10^{-5} \mathrm{M}\right)$ at $0^{\circ} \mathrm{C}$ for $20 \mathrm{~min}$ in choline-free Krebs-Ringer solution. Then it was incubated with $5 / \mathrm{M}$ choline in the absence or presence of a thiol compound at $38^{\circ} \mathrm{C}$ for $4 \mathrm{~min}$. The radioactivity taken up by the crude synaptosomal preparation was determined.

Effect of washing with the medium containing thiol compound on MMCinhibited high affinity choline uptake: The crude synaptosomal preparation was preincubated with $\mathrm{MMC}\left(2 \times 10^{-5} \mathrm{M}\right)$ at $0^{\circ} \mathrm{C}$ for $10 \mathrm{~min}$ and incubated at $0^{\circ} \mathrm{C}$ for $20 \mathrm{~min}$ with $0,1,3$, or 9 volumes of $0.32 \mathrm{M}$ sucrose solution ( $\mathrm{pH}$ 6.0) containing a thiol compound (final concentration: $0,10^{-6}, 10^{-5}$, and $10^{-4} \mathrm{M}$ ). It was centrifuged and the resulting pellet was resuspended in the original volume of $0.32 \mathrm{M}$ sucrose solution to examine high affinity choline uptake.

Determination of radioactivity: The radioactivity of the sample was determined by a liquid scintillation spectrometer (LSC model 651. Aloka Co.. Tokyo) with vials containing $10 \mathrm{ml}$ of Bray's solution (24).

Chemicals: Methyimercury chloride and 2. 3-dimercaptosuccinic acid were purchased from the Wako Pure Chemical Industries, Ltd. Osaka: D-penicillamine and neostigmine bromide from the Nakarai Chemical Industries Ltd., Tokyo: Dowex $1 \times 8$ (200-400 mesh. chloride type) was from the Muromachi Chemical Industries, Ltd., Tokyo; and some of other chemicals were from the Kanto Chemical Co., Ltd., Tokyo.

RESULTS

Effect of D-penicillamine and dimercaptosuccinic acid on MMC-inhibited ChAT activity: MMC inhibited the ChAT activity
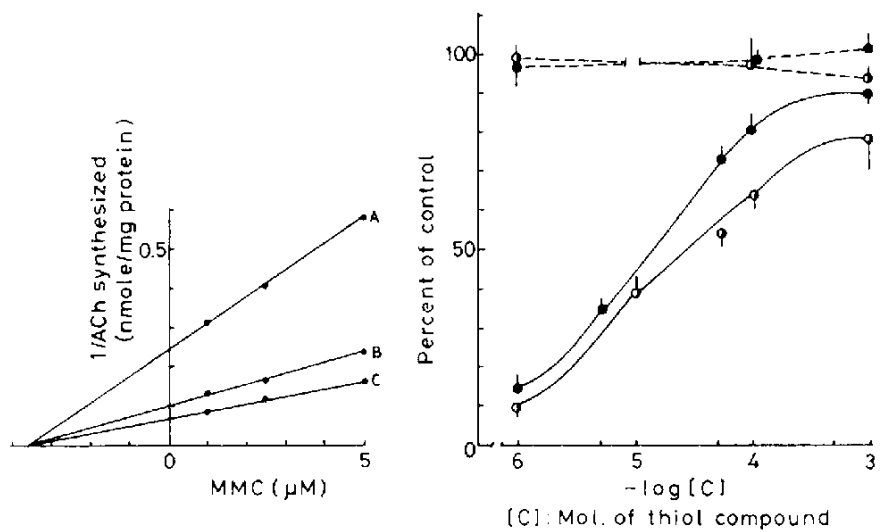

Fig. 1. Inhibition of ChAT activity by MMC and effects of D-penicillamine and dimercaptosuccinic acid on MMC-inhibited ChAT activity. Left panel: Dixon analysis (25) of MMC-inhibition of ChAT activity. The point of intersection of the lines shows the Ki to be $3.38 \mu \mathrm{M}$ of $\mathrm{MMC}$. Lines $\mathrm{A}, \mathrm{B}$, and $\mathrm{C}$ are data at reaction medium choline concentration of $0.1,0.3$, and $0.5 \mathrm{mM}$, respectively. Right panel: D-Pc or DMS was added to a ChAT preparation which was untreated (dotted line) or pretreated (solid line) with $7.5 \times 10^{-6} \mathrm{MMMC}$ at ${ }^{\circ} 0 \mathrm{C}$ for $5 \mathrm{~min}$. The results are plotted as percents of those obtained from the control (intact ChAT preparation). The control value was $1.7 \pm 0.2 \mathrm{mmole} A \mathrm{Ch}$ synthesized/mg protein/min. Data are expressed as the meantS.D. $(n=4)$. O: D-PC, o: DMS. 
noncompetitively with a $\mathrm{Ki}$ of $3.38 \pm 0.28 \mu \mathrm{M}$ which was evaluated by a Dixon plot (25) (Fig. 1). Figure 1 shows the effects of D-PC and DMS on the ChAT activity which had been previously inhibited almost completely by $10^{-4} \mathrm{M} M M C$. The effects were expressed as the percent of non-inhibited ChAT activity (control). The control value was $1.7 \pm 0.2$ $\mathrm{mmole}$ ACh synthesized/mg protein $/ \mathrm{min}$.

$D-P C$ and DMS in the range of $10^{-6}$ to $10^{-3} \mathrm{M}$ reactivated the $\mathrm{MMC}$-inhibited ChAT activity dose-dependently. The ED50 of D-PC and DMS to produce a $50 \%$ reactivation were $1.2 \pm 0.2$ and $3.3 \pm 0.6 \times 10^{-5} \mathrm{M}$. respectively. Neither of them up to a concentration of $10^{-3} \mathrm{M}$ could restore the activity completeIy. The reversible effect on the $M M C$-inhibited ChAT activity was significantly greater with D-PC than with DMS. Neither of them alone up to a concentration of $10^{-3} \mathrm{M}$ had an appreciable effect on the ChAT activity (Fig. 1).

Effect of dialysis on MMC-inhibited ChAT activity against buffer containing $\mathrm{D}-\mathrm{Pc}$ or DMS: In order to remove MMC which was bound to ChAT, equilibrium dialysis was conducted by adding D-PC or DMS to the outer solution. As shown in Fig. 2, no reactivation was observed when MMCinhibited ChAT was dialyzed against the thial compound-free phosphate buffer over a period of $6 \mathrm{hr}$. The dialysis against the buffer containing $10^{-3} \mathrm{M} \mathrm{D-PC}$ or DMS reversed time-dependently the ChAT activity which had previously been inhibited almost completely by MMC. After a 6-hr dialysis against D-PC-buffer, the activity in the dialysate was $74 \%$ of that in the intact non-dialyzed ChAT preparation.

On the other hand, the dialysis of an intact ChAT preparation for $6 \mathrm{hr}$ reduced the activity to about $87 \%$ of the original. No significant difference in ChAT activity was seen between the D-Pc-dialyzed preparation and the dialyzed-intact one after $6 \mathrm{hr}$. Thus,

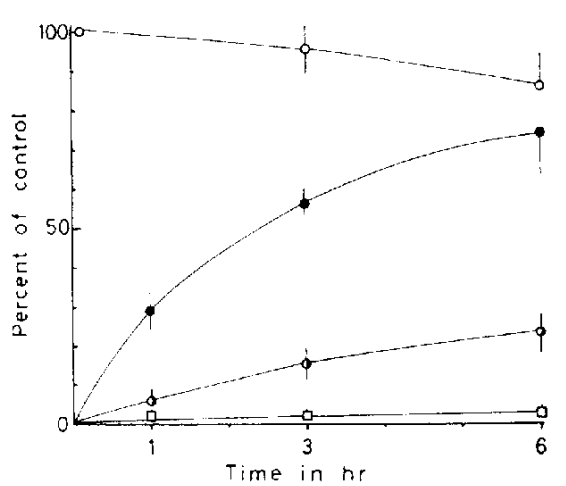

Fig. 2. Effect of dialysis against thiol compoundcontaining buffer on MMC-inhibited ChAT activity. The ChAT preparation pretreated with $4 \times 10^{-4} \mathrm{MMMC}$ at $0^{\circ} \mathrm{C}$ for $10 \mathrm{~min}$ was dialyzed against $1000 \mathrm{ml}$ of phosphate buffer (D). $10^{-3} \mathrm{M} \mathrm{D-PC-containing} \mathrm{phosphate} \mathrm{buffer}(\mathbf{)})$, or $10^{-3} \mathrm{M}$ DMS-containing phosphate buffer (J) at $0^{\circ} \mathrm{C}$ for $1-6 \mathrm{hr}$. The intact ChAT preparation (O) was also dialyzed against phosphate buffer under the same conditions. The ChAT activity of the nondialyzed intact ChAT preparation as a control was expressed as $100 \%$ reactivation. The control value was $1.9 \pm 0.5$ mmole ACh synthesized/mg protein/min. Data are expressed as the mean \pm S.D. $(n=4)$.

almost total reactivation of $\mathrm{MMC}$-inhibited ChAT was induced by dialyzing against the buffer containing D-PC. On the other hand, the dialysis of the MMC-inhibited ChAT against the buffer containing $10^{-3} \mathrm{M}$ DMS caused less reactivation than dialyzing against buffer containing $10^{-3} \mathrm{MD}-\mathrm{PC}$ (Fig. 2).

Effect of D-penicillamine and dimercaptosuccinic acid on MMC-inhibited high affinity choline uptake: The high affinity uptake of choline by the crude synaptosomal preparation used indicated the $\mathrm{Km}$ to be $3.53 \pm 0.92 / \mathrm{M}$ choline which was in good agreement with the data reported by others (26. 27). As shown in Fig. 3, MMC inhibited the high affinity choline uptake noncompetitively with a $\mathrm{Ki}$ of $3.74 \pm 0.28 \mu \mathrm{M}$ which was evaluated by Dixon plot (25). MMC at a concentration of $2 \times 10^{-5} \mathrm{M}$. which was about 5 times as high as the $K i$ value. 

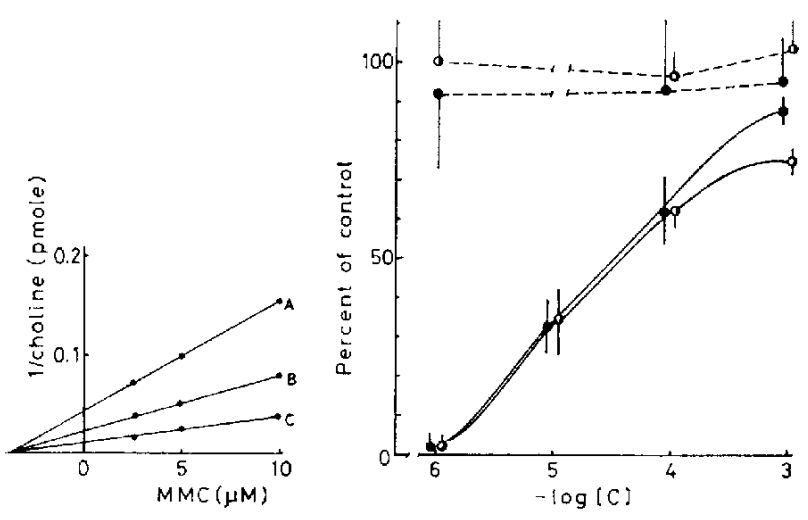

(C): Mol. of thiol compound

Fig. 3. Inhibition of high affinity choline uptake by MMC and effects of thiol compounds on MMC-inhibited high affinity choline uptake. Left panel: Dixon analysis (25) of MMCinhibition of high affinity choline uptake. The point of intersection of the lines shows the $\mathrm{Ki}$ to be $3.74, a \mathrm{M} \mathrm{MMC}$. Lines $\mathrm{A}, \mathrm{B}$, and $\mathrm{C}$ are data for reaction medium choline concentrations of $1.0,3.0$, and $5.0 \mu \mathrm{M}$, respectively. Right panel: The crude synaptosomal preparation which had been untreated (dotted line) or pretreated (solid line) with $2 \times 10^{-5}$ M MMC was incubated at $38^{\circ} \mathrm{C}$ for 4 min in a medium containing $5 \mu \mathrm{M}$ choline $(0.5 \mu \mathrm{Ci}$ of ${ }^{4} \mathrm{C}$-choline) in the presence of D-Pc $(0)$ or DMS $(\mathbf{O})$. The radioactivity taken up by the preparation was determined. Data are expressed as percent of the control $(n=4)$. The control value was $7.5 \pm 2.1$ pmole choline $/ \mathrm{mg}$ protein/min.

inhibited the high affinity uptake of choline almost completely. The control value was $7.5 \pm 2.1 \mathrm{pmole} / \mathrm{mg}$ protein $/ \mathrm{min}$. D-PC and DMS equally reversed the MMC-inhibited high affinity uptake of choline in a dosedependent fashion (Fig. 3). The ED50 values of D-PC and DMS to produce a $50 \%$ reactivation of the high affinity uptake of choline were $6.1 \pm 1.0$ and $5.7 \pm 0.5 \times 10^{-5} \mathrm{M}$. respectively. D-PC or DMS itself in a range of $10^{-6}$ to $10^{-3} \mathrm{M}$ had no appreciable effect on the high affinity uptake of choline (Fig. 3).

Effect of washing with $0.32 \mathrm{M}$ sucrose solution containing D-PC or DMS: The crude synaptosomal preparation in which the high affinity choline uptake had been previously almost completely inhibited by MMC was resuspended in 1, 3, and 9 volumes of $0.32 \mathrm{M}$ sucrose solution containing $10^{-6}$ to $10^{-4} \mathrm{M}$ $\mathrm{D}-\mathrm{PC}$ or DMS. Figure 4 shows the high affinity choline uptake by the suspension of centrifugal pellet. It is expressed as the percent of that of the intact preparation. Washing with a solution containing D-PC or DMS reversed the MMC-inhibited high affinity choline uptake dose-dependently; almost no appreciable effect was seen when $0.32 \mathrm{M}$ sucrose solution alone was used as a washing solution.

Effect of D-PC and DMS on high affinity choline uptake inhibited by hemicholinium-3: $\mathrm{HC}-3$ inhibited competitively the high affinity uptake of choline with a Ki of $0.08 \pm 0.03 \mu \mathrm{M}$ (evaluated by Dixon plot), which was in good agreement with data reported by others (26. 27). D-PC and DMS up to a concentration of $10^{-3} \mathrm{M}$ failed to have any appreciable effect on the high affinity uptake of choline inhibited by $\mathrm{HC}-3$ (data not shown).

\section{DISCUSSION}

The inhibitory effects of MMC on ChAT activity and high affinity choline uptake appear to be attributed to the interference with sulfhydryl groups around or at their active sites since mercury has a high affinity for 


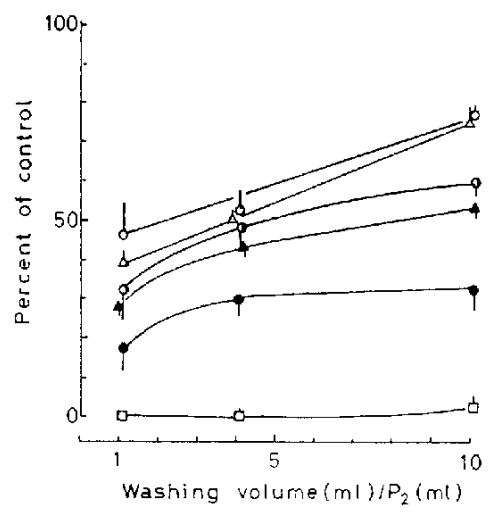

Fig. 4. Effect of washing with $0.32 \mathrm{M}$ sucrose solution containing a thiol compound on MMCinhibited high affinity choline uptake. The crude synaptosomal preparation was pretreated with $10^{-4} \mathrm{M} M M C$ at $0^{\circ} \mathrm{C}$ for $10 \mathrm{~min}$ and then suspended in $0.32 \mathrm{M}$ sucrose solution containing $0-10^{-4} \mathrm{M}$ D-PC or DMS in a volume of 1,3 , and $9 \mathrm{ml}$ per $\mathrm{ml}$ of the crude synaptosomal preparation. After being allowed to stand at $0^{\circ} \mathrm{C}$ for $10 \mathrm{~min}$, the resulting suspensions were centrifuged at $3 \times 10^{4} \mathrm{~g}$ for $40 \mathrm{~min}$ at $0^{\circ} \mathrm{C}$. Their pellets were resuspended in $0.32 \mathrm{M}$ sucrose solution in the volume of the original preparation. The high affinity choline uptake of $0.1 \mathrm{ml}$ of the resuspension was expressed as the mean percent of the control (untreated original crude synaptosomal preparation). The control value was $7.2 \pm 2.3$ pmole $/ \mathrm{mg}$ protein $/ \mathrm{min}$. O: $10^{-4} \mathrm{M}$ D-Pc, $10^{-5} \mathrm{M}$ D-PC, $10^{-6} \mathrm{M}$ D-Pc, $\triangle$ : $10^{-4} \mathrm{M}$ DMS, $\triangle: 10^{-5} \mathrm{M}$ DMS, $\square$ : only $0.32 \mathrm{M}$ sucrose solution. Data are expressed as the mean \pm S.D. $(n=4)$.

these groups. It is known, however, that methylmercury can also inhibit non-SH enzymes (18). ChAT has long been considered an $\mathrm{SH}$ enzyme with a cysteine residue near or at the active site $(8,28,29)$. The inhibitory effect of MMC on ChAT activity was a noncompetitive mode of action and could be reversed dose-dependently by thial compounds. From this result, it was suggested that this inhibitory effect might mainly be attributed to binding with sulfhydryl group(s) near or around the active site of ChAT. Mannervik and Sörbo (8) indicated that the sulfhydryl group might not be at the active site of ChAT. D-PC and DMS did not have the same reactivating effect on MMC-inhibited ChAT activity. Although the chelating effect of a thiol compound is generally thought to be greater than that of monothiol one, D-PC was more effective than DMS in reactivating inhibited ChAT activity. Several possible explanations have been made for the difference in such an effect: ChAT may have hydrophobic properties $(8,28,30,31)$ : MMC may be hydrophobic (31): ChAT does not require a dithiol group for activity (8): BAL, a hydrophobic dithiol compound, may be less effective in binding organic mercury than water-soluble inorganic mercury (31): DMS may be a water-soluble derivative of BAL $(10-12)$. It is reported that water-soluble sulfhydryl compounds such as iodoacetate. mercuric nitrate, and $\mathrm{N}$-ethylmaleimide cannot inhibit or can inhibit ChAT activity only at higher concentrations $\left(10^{-4} \mathrm{M}\right.$ or more) (4, 8). Therefore. DMS might not be able to come close to the site of ChAT. to which $\mathrm{MMC}$ is bound, and might be less effective in binding MMC than D-Pc, which is water-and alcohol-soluble.

In an equilibrium dialysis experiment D$\mathrm{PC}$ reactivated the $\mathrm{MMC}$-inhibited ChAT activity almost completely. Accordingly, the effect of D-PC seems to be attributed mainly to a removal of MMC from ChAT.

The inhibitory effect of MMC on the high affinity choline uptake was a noncompetitive mode of action and could be reversed dose. dependently by D-PC and DMS. From these results, it was suggested that this inhibitory effect might mainly be attributed to binding a sulfhydryl group(s) which participates in the mechanism of high affinity choline uptake in brain synaptosomes. Although the mechanism of the high affinity choline uptake is fully unknown, it has been postulated to involve a transport carrier which is localized almost at the presynaptic terminal membrane of the chalinergic nerve $(28,29,32)$. The active site of the carrier appears to have an 
anionic site and a $\mathrm{H}$-bonding site (33). It is, however, reported that inhibitors of high affinity choline uptake could conceivably interact not only with the active site(s), but with adjacent sites (for example, hydrophobic moiety. SH-group) (34). Ouabain, an inhibitor of the $\mathrm{Na}^{+}, \mathrm{K}^{+}$-ATPase can inhibit high affinity choline uptake (35). MMC is a potent inhibitor of the $\mathrm{Na}^{+}, \mathrm{K}^{+}$ATPase, an SH-enzyme (36). It seems, therefore, conceivable that MMC might inhibit the high affinity choline uptake at a site adjacent to the carrier active site such as a hydrophobic moiety or a sulfhydryl group embedded in the synaptosomal membrane, and/or inhibit $\mathrm{Na}^{+}, \mathrm{K}^{+}$-ATPase activity. Baba et al. (19) reported that cysteine partly reactivated high affinity choline uptake which had previously been inhibited by p-hydroxymercuric benzene sulfonate. In the present experiment, despite the difference in the number of $\mathrm{SH}$ groups in the molecules, D-PC and DMS within a range of $10^{-6}-10^{-3} \mathrm{M}$ equally reactivated high affinity choline uptake which had been previously inhibited by MMC. Bondy et al. (7) found that MMC and mercuric chloride, which is hydrophilic. equally inhibited high affinity choline uptake. It is also reported that water-soluble sulfhydryl compounds such as $\mathrm{N}$-ethylmaleimide and iodoacetate can potently inhibit high affinity choline uptake (33). Thus, a possible explanation is that the site of high affinity choline uptake may be less hydrophobic than the active site of ChAT.

Since washing with a solution containing D-PC or DMS reversed dose-dependently the high affinity choline uptake which had previously been inhibited by MMC, this reversible effect might be attributed to the elimination of methylmercury from the site of binding. Neither D-PC nor DMS could reactivate the $M M C$-inhibited high affinity choline uptake completely. Since heavy metals also have an affinity for groups other than the sulfhydryl group such as hydroxyl. carbonyl, phosphate, and amino groups ( 9 . 37 ), thiol chelating compounds used in the present experiment might not be able to remove MMC completely.

The inhibitory effect of $\mathrm{HC}-3$ on high affinity choline uptake was a competitive mode of action and could not be reversed by $\mathrm{D}-\mathrm{PC}$ or DMS. Therefore, the inhibitory mechanism of $\mathrm{HC}-3$ may be different from that of MMC and may not have been exerted on the thiol groups.

In conclusion, the results of this study indicate that MMC inhibits ChAT activity and high affinity choline uptake mainly via SH group(s), from which such thiol-chelating compounds as D-PC and DMS may eliminate MMC. A thiol compound, such as D-PC, which is both hydrophobic and hydrophilic rather than only hydrophilic and contains more than one SH group, may have an effect of reversing the MMC-inhibited cholinergic system.

Acknowledgements: The authors wish to thank Mr. K. Obonai for technical assistance.

\section{REFERENCES}

1) Hunter, D. and Russel1, D.S.: Focal cerebral and cerebellar atrophy in a human subject due to organic mercury compounds. J. Neurol. Neurosurg. Psychiat. 17. 235-241 (1954)

2) Miyakawa, T.: Mechanism of pathological changes of cells induced by organic mercury compound in Minamata disease. Adv. Neurol. Sci. 17, 745-752 (1973)

3) Miyakawa, T. and Deshimaru, M.: Electronmicroscopic study of experimentally induced poisoning due to organic mercury compound. Acta Neuropathol. (Berl.) 14, 126-136 (1969)

4) Kobayashi, H., Yuyama, A., Matsusaka, N., Takeno, $\mathrm{K}$. and Yanagiva, 1.: Effects of methylmercury chloride on various cholinergic parameters in vitro. J. toxicol. Sci, 4, 351-362 (1979)

5) Kobayashi, H., Yuyama, A., Matsusaka, N., Takeno, $K$. and Yanagiya, I.: Effect of methylmercury on brain acetylcholine concentration and turnover in mice. Toxicol. appl. Pharmacol. 54, 1-8 (1980) 
6) Kobayashi, H., Yuyama, A., Matsusaka, N., Takeno, $K$. and Yanagiya, I.: Neuropharmacological effect of methylmercury in mice with special reference to the central cholinergic system. Japan. J. Pharmacol. 31, 711-718 (1981)

7) Bondy, S.C., Anderson, C.L., Harrington, M.E. and Prasad, K.N.: The effects of organic and inorganic lead and mercury on neurotransmitter high-affinity transport and release mechanism. Environ. Res. 19, 102-111 (1979)

8) Mannervik, B. and Sörbo, B.: Inhibition of choline acetyltransferase from bovine caudate nucleus by sulfhydryl reagents and reactivation of the inhibited enzyme. Biochem. Pharmacol. 19, 2509-2516 (1970)

9) Berg, G.G. and Miles, E.F.: Mechanisms of inhibition of active transport ATPase by mercurials. Chem. Biol. Interact. 27, 199-219 (1979)

10) Friedheim, E, and Corvi, C.: Meso-dimercaptosuccinic acid, a chelating agent for the treatment of mercury poisoning. J. Pharm. Pharmacol. 27, 624-626 (1975)

11) Friedheim, E., Corvi, C. and Wakker, C.H.: Meso-dimercaptosuccinic acid, a chelating agent for the treatment of mercury and lead poisoning. J. Pharm. Pharmacol. 28, 711--712 (1976)

12) Magos, L.: The effects of dimercaptosuccinic acid on the excretion and distribution of mercury in rats and mice treated with mercuric chloride and methylmercury chloride. Brit. J. Pharmacol. 56, 479-484 (1976)

13) Gabard, B.: Treatment of methylmercury poisoning in the rat with sodium 2,3-dimercaptopropane-1-sulfonate: influence of dose and mode of administration. Toxicol. appl. Pharmacol. 38, 415-424 (1976)

14) Zimmer, L.J. and Carter, D.E.: The efficacy of 2. 3-dimercaptopropanol and D-penicillamine on methylmercury induced neurological signs and weight loss. Life Sci. 23, 1025-1034 (1978)

15) Aaseth, J. and Friedheim, E.A.H.: Treatment of methyl mercury poisoning in mice with 2, 3 dimercaptosuccinic acid and other complexing thiols. Acta Pharmacol. Toxicol. 42, 248-252 (1978)

16) Magos, L., Peristianis, G.C. and Snowden, R.T. Post exposure preventive treatment of methylmercury intoxication in rats with dimercaptosuccinic acid. Toxicol. appl. Pharmacol. 45, 463475 (1978)

17) Sanyal, G. and Khalifah, R.G.: Kinetics of organomercurial reactions with model thiols: Sensitivity to exchange of the mercurial label ligand. Arch. Biochem. Biophys. 196, 157-164 (1979)

18) Waku, K. and Nakazawa, Y.: Toxic effects of several mercury compounds on $\mathrm{SH}$-and non-SH enzymes. Toxicol. Lett. 4, 49-55 (1979)

19) Baba, A., Fischerman, J.S. and Cooper, J.R.: Action of sulfhydryl reagents on cholinergic mechanisms in synaptosomes. Biochem. Pharmacol. 28, 1879-1883 (1979)

20) Ebashi, S.: Enzymes responsible for acetylation via acetyl-SCoA. in Methods in Enzymology. Edited by Akabori S., Vol. 3, p. 308. Asakura Shoten. Tokyo (1957) (in Japanese)

21) Shrier, B.K. and Shuster, L: A simplified radiochemical assay for choline acetyltransferase. J. Neurochem. 14, 977-985 (1967)

22) Gray, G. and Whittaker, V.P.: The isolation of endings from brain: An electronmicroscopic study of cell fragments derived from homogenization and centrifugation. J. Anat. 96, 7987 (1962)

23) Murrin, L.C., Dehaven, R.N. and Kuhar, M.J.: On the relationship between ${ }^{3} \mathrm{H}$-choline uptake activation and $3 \mathrm{H}$-acetylcholine release. J. Neurochem. 29, 681-687 (1977)

24) Bray, G.A: A simple efficient liquid scintillator for counting aqueous solution in a liquid scintillation counter. Analyt. Biochem. 1, 279$285(1960)$

25) Dixon, M.: The determination of enzyme inhibitor constants. Biochem. J. 55, 170-171 (7953)

26) Yamamura, H.I. and Snyder, S.H.: High affinity transport of choline into synaptosomes of rat brain. J. Neurochem. 21, 1355-1374 (1973)

27) Barker, L.A. and Mitaag, T.W.: Comparative studies of substrates and inhibitors of choline transport and choline acetyltransferase. J. Pharmacol. exp. Ther. 192, 86-94 (1975)

28) Chao, L.-P.: Choline acetyltransferase: Purification and characterization. J. Neurosci. Res. 5, 85-115 (1980)

29) Hebb, C.: Biosynthesis of acetylcholine in nervous tissue. Physiol. Rev, 52, 918-957 (1972)

30) Rossier, J.: Acetyl-coenzyme A and coenzyme $A$ analogues. Their effects on rat brain choline acetyltransferase. Biochem J. 165, 321-326 (1977)

31) Zimmer, L. and Carter, D.E.: Effects of complexing treatment administered with the onset of methylmercury neurotoxic signs. Toxicol. appl. Pharmacol. 51, 29-38 (1979)

32) Jope, R.S.: High affinity choline transport and acetyl CoA production in brain and their roles in the regulation of acetylcholine synthesis. 
Brain Res. Rev. 1, 313-344 (1979)

33) Batzold, F., Dehaven, R., Kuhar, M.J. and Birdsall, N.: inhibition of high affinity choline uptake. Structure activity studies. Biochem. Pharmacol. 29, 2413-2416 (1980)

34) Fisher, A. and Hanin, 1.: Minireview. Choline analogs as potential tools in developing selective animal models of central cholinergic hypofunction. Life Sci. 27, 1615-1634

35) Beach, R.L., Vaca, K. and Pilar, G.: Ionic and metabolic requirements for high-affinity choline uptake and acetylcholine synthesis in nerve terminals at a neuromuscular junction. J. Neurochem. 34, 1387-1398 (1980)

36) Jacobson, M.S., Chan, T, and Okita, G.T.: In vitro inhibition of $\mathrm{Na}^{+}, \mathrm{K}^{+}$- ATPase by methylmercury. Fedn Proc. 31, 561 (1972)

37) Vallee, B.L. and UImer, D.D.: Biochemical effects of mercury, cadmium, and lead. Ann. Rev. Biochem. 41, 91-128 (1972) 